Original Article

\title{
Factors Related to Gait Function in Post-stroke Patients
}

\author{
Ki Hun Cho, PT, PhD'), Joo Young Lee, MD²), Kun Jae LeE ${ }^{3)}$, Eun Kyoung Kang, MD, PhD ${ }^{3)^{*}}$ \\ 1) Department of Rehabilitative and Assistive Technology, Korea National Rehabilitation Research \\ Institute, Republic of Korea \\ 2) Department of Rehabilitation Medicine, Seoul Bukbu Hospital, Republic of Korea \\ 3) Department of Rehabilitation Medicine, Kangwon National University College of Medicine: Baeng- \\ nyeong-ro 156, Chuncheon-si, Gangwon-do 200-722, Republic of Korea
}

\begin{abstract}
Purpose] Gait function after a stroke is an important factor for determining a patient's ability to independently perform activities of daily living (ADL). The objective of this study was to elucidate the factors associated with gait function in post-stroke patients. [Subjects] Thirty-nine stroke patients (16 females and 23 males; average age $67.82 \pm 10.96$ years; post-onset duration: $200.18 \pm 27.14$ days) participated in this study. [Methods] Their gait function, motor function (Manual Muscle Test [MMT] and Brünnstrom stage), level of cognition (Mini-Mental State Examination score [MMSE], and the Loewenstein Occupational Therapy Cognitive Assessment for the Geriatric Population [LOTCA-G]), and ADL (Korean modified Barthel index [K-MBI]) were assessed. [Results] The degree of gait function showed significant positive correlations with the following variables: MMT of the elbow, knee, ankle and wrist; Brünnstrom stage; MMSE; LOTCA-G subscores except motor praxis; K-MBI. Stepwise linear regression analysis revealed the Brünnstrom stage was the only explanatory variable closely associated with gait level. [Conclusion] Gait function of post-stroke patients was related to motor function, cognition, and ADL. In particular, there is a significant association between gait level and the Brünnstrom stages, reflecting the importance of monitoring the motor recovery of gait function in post-stroke patients.

Key words: Stroke, Gait, Brünnstrom stage
\end{abstract}

(This article was submitted May 13, 2014, and was accepted Jun. 17, 2014)

\section{INTRODUCTION}

Gait function is an important factor that determines the degree of physical ability of post-stroke patients and their ability to perform independent mobility during activities of daily living $(\mathrm{ADL})^{1)}$. In previous studies, while $37 \%$ of stroke survivors were able to walk one week after the stroke, and $50 \%$ of those did regain gait function ${ }^{2}$, $30 \%$ of patients with stroke were unable to walk again ${ }^{3)}$.

Other studies have reported that gait function is related to isokinetic torques of the paretic lower extremity ${ }^{4}$. Some studies focused on simple walking speed and have demonstrated an association between cognitive function and motor performance ${ }^{5)}$. Therefore, the current literature suggests that gait is the combined result of muscle movement of the leg, the interlimb coordination pattern, and cognitive function $^{6}$.

In practice, these factors, which are important for the recovery of gait function following stroke, are critical for

*Corresponding author. Eun Kyoung Kang (E-mail: stewardofgod@gmail.com)

(C2014 The Society of Physical Therapy Science. Published by IPEC Inc. This is an open-access article distributed under the terms of the Creative Commons Attribution Non-Commercial No Derivatives (by-ncnd) License $<$ http://creativecommons.org/licenses/by-nc-nd/3.0/> . developing therapeutic strategies designed to maximize participation and minimize disability ${ }^{7}$. However, the single most influential factor determining gait function in poststroke patients is not clear. Thus, the aim of the present study was to gain a more comprehensive understanding of the factors related to gait function in post-stroke patients.

\section{SUBJECTS AND METHODS}

This study used a cross-sectional design. The medical records of patients admitted to a rehabilitation hospital after acute stroke from October 2011 to October 2012 were retrospectively reviewed. The records of patients admitted due to traumatic brain injury, brain tumor, or neurodegenerative diseases were excluded. All patients underwent a standardized rehabilitation program consisting of physical and occupational therapy from the day after they were admitted. This study, a retrospective review of the patients' medical records, was approved by the Institutional Review Board of Kangwon National University Hospital (IRB No. 201312-004).

All assessments were evaluated by licensed physical and occupational therapists within the first week of admission. Gait level (GL) was assessed using six levels; GL1 indicates gait with complete dependence; GL2, maximum assistance; GL3, moderate assistance; GL4, minimum assistance; GL5, supervision required; and GL6, complete independence. 
Muscle strength was measured by Manual Muscle Test (MMT) with a score from 0 to $5^{8}$. MMT was determined based on the power of elbow flexion, wrist extension, knee extension, and ankle dorsiflexion. The Brünnstrom stage (BS) was used to assess the motor recovery of the paretic lower limb ${ }^{9)}$ and was categorized as: BS1, flaccid; BS2, the development of synergy pattern with minimal voluntary movements; BS3, voluntary synergistic movement combined with hip flexion, knee flexion, and ankle dorsiflexion while in the sitting and standing positions; BS4, some movements, apart from synergy pattern, such as knee flexion exceeding $90^{\circ}$ and ankle dorsiflexion with the heel on the floor in the sitting position were observed; BS5, independent movement apart from the basic synergic pattern; and BS6, isolated voluntary joint movements. The BS quantifies the function of motor control based on clinical assessment of movement quality.

The Mini-Mental State Examination (MMSE) was used to assess cognitive function. The MMSE is comprised of tests for orientation, memory, attention, calculation, language, and construction functions (total score between 0-30) ${ }^{10)}$. The Loewenstein Occupational Therapy Cognitive Assessment for the Geriatric Population (LOTCA-G) was also used to assess cognitive function. It is composed of tests for orientation (0-16), visuospatial perception (0-28), praxis $(0-12)$, visuomotor organization $(0-24)$, thinking operation $(0-8)$, memory $(0-12)$, and attention $(0-4)$.

Activities of daily living (ADL: total score between 0 and 100) were measured using the Korean version of the modified Barthel index (K-MBI). K-MBI evaluates 10 different areas of ADL: feeding, transfer, grooming, toilet use, bathing, mobility, ascending and descending stairs, dressing, and bowel and bladder control ${ }^{11)}$. The physical therapists evaluated gait and motor functions and the occupational therapists evaluated the levels of cognition and ADL.

Data were analyzed using SPSS for Windows version 18.0 (SPSS Inc., Chicago, IL, USA). Pearson and Spearman correlation coefficients were used to evaluate the relationships among the variables. Stepwise linear regression analysis was used to elucidate the explanatory factor associated with gait function. Statistical significance was accepted for values of $p<0.05$. Data are presented as the mean with standard deviation (SD) values.

\section{RESULTS}

The clinical characteristics of the patients (16 females and 23 males; average age $67.82 \pm 10.96$ years; post-onset duration: $200.18 \pm 27.14$ days) are shown in Table 1 .

The level of gait function showed significant positive correlations with the following variables; MMT of the elbow $(\gamma=0.658, p<0.001)$, wrist $(\gamma=0.517, p=0.001)$, knee $(\gamma=0.574, p<0.001)$, and ankle $(\gamma=0.557, p<0.001)$; Brünnstrom stage $(\gamma=0.736, \mathrm{p}<0.001)$; MMSE $(\gamma=0.375$, $\mathrm{p}=0.019) ;$ LOTCA-G subscores $(\gamma=0.368-0.480, \mathrm{p}<0.05)$ except motor praxis $(\gamma=0.275, \mathrm{p}=0.090)$; K-MBI $(\gamma=0.634$, $\mathrm{p}<0.001$ ) (Table 2).

Stepwise linear regression analysis revealed that the Brünnstrom stage $\left(r^{2}=0.500, \mathrm{~F}=46.308, \mathrm{p}<0.001\right)$ was the
Table 1. Clinical characteristics of the stroke patients

\begin{tabular}{|c|c|}
\hline Variables & \\
\hline \multicolumn{2}{|l|}{ Gender } \\
\hline Female/Male (\%) & $16 / 23(41.0 / 59.0)$ \\
\hline \multicolumn{2}{|l|}{ Stroke etiology } \\
\hline Infarction/ Hemorrhage (\%) & $25 / 14(64.1 / 35.9)$ \\
\hline \multicolumn{2}{|l|}{ Affect side } \\
\hline Right/Left (\%) & $19 / 20(48.7 / 51.3)$ \\
\hline Age (years) & $67.8 \pm 0.9$ \\
\hline Post-onset duration (days) & $200.1 \pm 227.1$ \\
\hline Gait level $(0-6)$ & $3.6 \pm 1.5$ \\
\hline \multicolumn{2}{|l|}{ MMT } \\
\hline Elbow flexor $(0-5)$ & $3.3 \pm 1.4$ \\
\hline Wrist extensor $(0-5)$ & $2.7 \pm 1.6$ \\
\hline Knee extensor $(0-5)$ & $3.7 \pm 1.2$ \\
\hline Ankle dorsiflexor $(0-5)$ & $2.7 \pm 1.6$ \\
\hline Brünnstrom stage (0-5) & $3.9 \pm 1.4$ \\
\hline $\operatorname{MMSE}(0-30)$ & $16.6 \pm 7.2$ \\
\hline \multicolumn{2}{|l|}{ LOTCA-G } \\
\hline Orientation $(0-16)$ & $8.1 \pm 5.1$ \\
\hline Visuospatial perception $(0-28)$ & $21.0 \pm 6.2$ \\
\hline Praxis $(0-12)$ & $9.1 \pm 3.0$ \\
\hline Visuomotor organization $(0-24)$ & $14.3 \pm 5.8$ \\
\hline Thinking operation $(0-8)$ & $3.6 \pm 2.1$ \\
\hline Memory $(0-12)$ & $8.6 \pm 2.8$ \\
\hline Attention (0-4) & $2.6 \pm 1.1$ \\
\hline Total score $(0-104)$ & $67.5 \pm 21.9$ \\
\hline K-MBI $(0-100)$ & $46.0 \pm 20.0$ \\
\hline
\end{tabular}

MMT: Manual Muscle Test, MMSE: Mini-Mental State Examination, LOTCA-G: Loewenstein Occupational Therapy Cognitive Assessment for the Geriatric Population, K-MBI: Korean version of the Modified Barthel Index

Values are mean $\pm \mathrm{SD}$

only explanatory variable closely associated with the level of gait function, indicating the importance of motor recovery in monitoring the level of gait function in post-stroke patients.

\section{DISCUSSION}

Better understanding of the factors that predict ambulatory function may assist with the development of individualized rehabilitation strategies for the various gait deficits of post-stroke patients ${ }^{6}$. . Thus, we performed this study to elucidate factors related to the gait ability in post-stroke patients.

Paralysis after stroke is an important factor related to an abnormal gait pattern. Since paralysis after stroke leads to dependence in ADL, it should be an important target of post-stroke rehabilitation ${ }^{12)}$. A previous study reported that the muscle strength of the paretic hip flexors and knee extensors is the most important factor for determining gait speed during comfortable and fast walking conditions ${ }^{13}$, and another study reported that walking independence shows a correlation with the muscle strength of the lower limb ${ }^{14)}$. In 
Table 2. Correlation coefficients of the measured variables with the gait level

\begin{tabular}{|c|c|}
\hline Variables & $\gamma$ \\
\hline \multicolumn{2}{|l|}{$\mathrm{MMT}^{\mathrm{a}}$} \\
\hline Elbow flexor (0-5) & $0.658 * * *$ \\
\hline Wrist extensor $(0-5)$ & $0.517 * * *$ \\
\hline Knee extensor $(0-5)$ & $0.574 * * *$ \\
\hline Ankle dorsiflexor $(0-5)$ & $0.557 * * *$ \\
\hline Brünnstrom stage $(0-5)^{\mathrm{a}}$ & $0.736^{* * *}$ \\
\hline $\operatorname{MMSE}(0-30)^{\mathrm{b}}$ & $0.375^{*}$ \\
\hline \multicolumn{2}{|l|}{ LOTCA-G ${ }^{b}$} \\
\hline Orientation $(0-16)$ & $0.345^{*}$ \\
\hline Visuospatial perception (0-28) & $0.392 *$ \\
\hline Praxis $(0-12)$ & 0.275 \\
\hline Visuomotor organization $(0-24)$ & $0.482 * *$ \\
\hline Thinking operation $(0-8)$ & $0.423 * *$ \\
\hline Memory $(0-12)$ & $0.356^{*}$ \\
\hline Attention $(0-4)$ & $0.438^{* *}$ \\
\hline Total score $(0-104)$ & $0.473 * *$ \\
\hline K-MBI $(0-100)^{\mathrm{b}}$ & $0.670 * * *$ \\
\hline \multicolumn{2}{|c|}{$\begin{array}{l}* \mathrm{p}<0.05, * * \mathrm{p}<0.01, * * * \mathrm{p}<0.001 \\
\text { MMT: Manual Muscle Test, MMSE: Mini-Mental State } \\
\text { Examination, LOTCA-G: Loewenstein Occupationa } \\
\text { Therapy Cognitive Assessment for the Geriatric Popu- } \\
\text { lation, K-MBI: Korean version of the Modified Barthe } \\
\text { Index } \\
\text { Analyzed by aSpearman's and bPearson's correlation } \\
\text { cofficients }\end{array}$} \\
\hline
\end{tabular}

the present study, MMT of the affected lower limbs showed a significant correlation with gait level. Therefore, we suggest that approaches to improve the muscle strength of the paretic leg must be considered during stroke rehabilitation for the improvement of ambulatory function.

The Brünnstrom stages reflect post-stroke motor recovery ${ }^{9)}$. A previous study using the Brünnstrom stages to measure motor recovery reported that the gait velocity of post-stroke patients showed a significant correlation with the status of motor recovery of the affected lower extremity $^{15)}$. Our findings demonstrate that the Brünnstrom stages are significantly correlated with gait level. Particularly, the Brünnstrom stages were the only remaining explanatory variable for gait ability in the regression analysis. These results imply that motor recovery influences physical functions such as walking. Impairment of muscle control or movement is the most common and widely recognized impairment caused by stroke. Therefore, stroke rehabilitation, particularly the work done by physical therapists and occupational therapists, largely focus on the recovery of motor impairment.

Gait is generally considered an autonomic process involving little or no higher cognitive input ${ }^{16}$. However, a recent study suggested that walking under usual circumstances may require attention and executive function ${ }^{17)}$. Other studies have used MMES and LOTCA to investigate relationships between cognition and the functional outcomes of patients with stroke ${ }^{18)}$. In particular, LOTCA-G subscores were shown to have high correlations with most parameters of functional motor outcomes ${ }^{18)}$. Therefore, we used MMSE and LOTCA-G to measure cognitive function. Our results show that gait ability is significantly correlated with the MMSE score and the LOTCA-G subscores, except that of motor praxis.

In this study, we investigated correlations between gait level and ADL performance to identify the effect of gait disturbance on the independence in ADL of patients with stroke. Our results show that there is a close correlation between gait level and K-MBI. This finding is consistent with previous studies ${ }^{19)}$, and we believe that the results of this study support the results of a previous study ${ }^{20)}$. We found that as gait level increases, patients with stroke perform ADL more independently ${ }^{21)}$ and participate more in social activities after discharge to home, even though they have a high risk of hospitalization ${ }^{22)}$. This study had several limitations, and one of them was the small sample size. Therefore, these results cannot necessarily be generalized to all stroke survivors. In addition, this study exclusively investigated physical and cognitive factors affecting gait, but not psychological factors. Thus, we believe that future research is required to examine potential relationships between gait level and psychological factors such as depression, anxiety, or stress.

In conclusion, this study investigated the physical and cognitive factors associated with gait function in poststroke patients. Gait function of post-stroke patients was related to muscle strength and motor recovery, cognition, and ADL. In particular, there was a significant association between gait level and the Brünnstrom stages. Therefore, the Brünnstrom stages should be assessed in post-stroke rehabilitation programs in order to enhance the improvement of gait ability.

\section{REFERENCES}

1) Tomoyuki S, Shigeru U: Association of ability to rise from bed with improvement of functional limitation and activities of daily living in hemiplegic inpatients with stroke: a prospective cohort study. J Phys Ther Sci, 2010, 22: 22-34.

2) Keenan MA, Perry J, Jordan C: Factors affecting balance and ambulation following stroke. Clin Orthop Relat Res, 1984, (182): 165-171. [Medline]

3) Friedman PJ: Gait recovery after hemiplegic stroke. Int Disabil Stud, 1990, 12: 119-122. [Medline] [CrossRef]

4) Kim CM, Eng JJ: The relationship of lower-extremity muscle torque to locomotor performance in people with stroke. Phys Ther, 2003, 83: 49-57. [Medline]

5) Fitzpatrick AL, Buchanan CK, Nahin RL, et al. Ginkgo Evaluation of Memory (GEM) Study Investigators: Associations of gait speed and other measures of physical function with cognition in a healthy cohort of elderly persons. J Gerontol A Biol Sci Med Sci, 2007, 62: 1244-1251. [Medline] [CrossRef]

6) Patterson SL, Forrester LW, Rodgers MM, et al.: Determinants of walking function after stroke: differences by deficit severity. Arch Phys Med Rehabil, 2007, 88: 115-119. [Medline] [CrossRef]

7) Robinson CA, Shumway-Cook A, Matsuda PN, et al.: Understanding physical factors associated with participation in community ambulation following stroke. Disabil Rehabil, 2011, 33: 1033-1042. [Medline] [CrossRef]

8) Bohannon RW: Manual muscle testing: does it meet the standards of an adequate screening test? Clin Rehabil, 2005, 19: 662-667. [Medline] [CrossRef]

9) Sawner KA, LaVigne JM, Brunnstrom S: Brunnstrom's movement therapy in hemiplegia: a neurophysiological approach, 2nd ed. Philadelphia: Lippincott, 1992.

10) Folstein MF, Folstein SE, McHugh PR: "Mini-mental state". A practical 
method for grading the cognitive state of patients for the clinician. J Psychiatr Res, 1975, 12: 189-198. [Medline] [CrossRef]

11) Jung HY, Park BK, Shin HS, et al.: Development of the Korean version of Modified Barthel Index (K-MBI): multi-center study for subjects with stroke. J Korean Acad Rehabil Med, 2007, 31: 283-297.

12) Flansbjer UB, Miller M, Downham D, et al.: Progressive resistance training after stroke: effects on muscle strength, muscle tone, gait performance and perceived participation. J Rehabil Med, 2008, 40: 42-48. [Medline] [CrossRef]

13) Hsu AL, Tang PF, Jan MH: Analysis of impairments influencing gait velocity and asymmetry of hemiplegic patients after mild to moderate stroke. Arch Phys Med Rehabil, 2003, 84: 1185-1193. [Medline] [CrossRef]

14) Fujita T, Iwata M, Fukuda M, et al.: Relationship between lower extremity muscle mass, leg extension strength and muscle power of hemiplegic stroke patients. J Phys Ther Sci, 2011, 23: 277-282. [CrossRef]

15) Brandstater ME, de Bruin H, Gowland C, et al.: Hemiplegic gait: analysis of temporal variables. Arch Phys Med Rehabil, 1983, 64: 583-587. [Medline]

16) Shik ML, Orlovsky GN: Neurophysiology of locomotor automatism. Physiol Rev, 1976, 56: 465-501. [Medline]

17) Sheridan PL, Solomont J, Kowall N, et al.: Influence of executive function on locomotor function: divided attention increases gait variability in
Alzheimer's disease. J Am Geriatr Soc, 2003, 51: 1633-1637. [Medline] [CrossRef]

18) Zwecker M, Levenkrohn S, Fleisig Y, et al.: Mini-Mental State Examination, cognitive FIM instrument, and the Loewenstein Occupational Therapy Cognitive Assessment: relation to functional outcome of stroke patients. Arch Phys Med Rehabil, 2002, 83: 342-345. [Medline] [CrossRef]

19) Lord SE, McPherson K, McNaughton HK, et al.: Community ambulation after stroke: how important and obtainable is it and what measures appear predictive? Arch Phys Med Rehabil, 2004, 85: 234-239. [Medline] [CrossRef]

20) Claesson L, Lindén T, Skoog I, et al.: Cognitive impairment after strokeimpact on activities of daily living and costs of care for elderly people. The Göteborg 70+ Stroke Study. Cerebrovasc Dis, 2005, 19: 102-109. [Medline] [CrossRef]

21) Lee SK, Lee SY, Park MC, et al.: The correlation of gait velocity, cadence and gait quality parameter using points of gait quality chart (GQC) items in hemiplegic patients. J Phys Ther Sci, 2011, 23: 765-767. [CrossRef]

22) Park HW, Lee YS, Noh JH: The discharge destinations of geriatric stroke patients admitted in the university hospitals. J Korean Geriatr Soc, 2007, 11: $24-30$. 